\title{
Experimental Study on Pretreatment of Preparing Phosphorus Building Gypsum with Yunnan Phosphogypsum
}

\author{
Chen-Xi DU ${ }^{1, a,{ }^{*}}$, Zhi-Man ZHAO ${ }^{2, b}$, Shuai LI ${ }^{3, \mathrm{c}}$, Zhi-Yu LIU ${ }^{4, \mathrm{~d}}$ \\ ${ }^{1}$ Faculty of Civil Engineering and Architecture, Kunming University of Science and Technology, \\ 650500, P. R. China \\ ${ }^{2}$ Yunna Kunming Steel Structure Co. ,Ltd, 650500, P. R. China \\ awoshiduchnxi@163.com, bIzd2005@126.com, ‘1130624808@qq.com, d286117907@qq.com \\ ${ }^{*}$ Corresponding author
}

Keywords: Phosphogypsum, Phosphorus Building Gypsum, Microwave Method, Pretreatmen.

\begin{abstract}
The effects of washing method, lime neutralization, flotation method and microwave method of different pretreatment process of Yunnan phosphorus building gypsum strength and crystal morphology. Through, a lot of experiments comparing the four kinds of pretreatment effect, the results show that: after four pretreatment of phosphogypsum are basically meet the requirements of the relevant provisions of building materials products; compared wih the other three methods, microwave method possessed the better effect of moving fluoride and organic matter in phosphorus gypsum,smaller losses of gypsum content,etc. Environmental protection, easy for factory operated, as well as high strength.
\end{abstract}

\section{Introduction}

According to the statistics of present, the whole world annual emissions of phosphogypsum are more than 150 million tons, but the utilization rate of phosphogypsum is only about $4 \%$.An annual output of 60000 tons of ammonium phosphate plant in our country, and every year ,the cost of the phosphogypsum piled up is over millions of dollars.Because of the emissions of phosphogypsum contained harmful material, the government not only increase the cost for occupied the large space to pile up,but also give rise to environmental pollution, harmful to human health and ecological environment. The needs of phosphogypsum for experiments are all from Yunnan Da Huanglin company that annually product phosphogypsum about $4 \sim 5$ million tons.

Phosphogypsum is a by-product of phosphorus industry, containing phosphorus, fluorine and organic impurities. The impurities affects the comprehensive utilization of phosphogypsum, such as fluorine impurities in conversion of gypsum formed in the reaction process difficult soluble calcium phosphate and calcium fluoride deposition on the surface of dihydrate gypsum, which will seriously affect the integrity of the dihydrate gypsum crystal growth, and cause the decline of the strength of the phosphorus building gypsum. Therefore, we need to pretreat the phosphogypsum before useing.Currently, there are three phosphogypsum pretreatment methods:the washing method, the flotation method and the lime neutralization method.The passage shows a new pretreatment method which is base on the traditional pretreatment,named microwave method[1-5].

The experiments of microwave method indicate that using the microwave method is more effective than other pretreatment methods to eliminate fluoride and organic phosphorus gypsum in phosphogypsum after pretreatment. And compared with other pretreatment methods and the content of calcium sulfate loss is smallest. The content of impurity results before and after pretreatment inTable 2.

\section{Experimental}

\section{The Raw Material}

Phosphogypsum. Producing Area :Yunnan Da Huanglin company.

Color: yellow gray. 
Moisture Content: $19.2 \%$.

PH Value :6.51.

Main Ingredients : $\mathrm{CaSO}_{4} \cdot 2 \mathrm{H}_{2} \mathrm{O}$, about $86.59 \%$, and its mineral composition Table 1.

Quicklime. Producing Area: Xilong Chemical co., LTD.

Main ingredients: market analysis of pure $\mathrm{CaO}, \mathrm{w} / \% \geq 98$.

Citric Acid. Producing Area: Chuanfeng Chemical Technology co., LTDin Tianjin

Main ingredients: market analysis of pure: $\mathrm{C}_{6} \mathrm{H}_{8} \mathrm{O}_{7} \cdot \mathrm{H} 2 \mathrm{O}, \mathrm{w} / \% \geq 99.5$.

Tab. 1 Phosphogypsum Component.

\begin{tabular}{cccccccc}
\hline component & $\mathrm{SiO}_{2}$ & $\mathrm{Al}_{2} \mathrm{O}_{3}$ & $\mathrm{TFe}_{2} \mathrm{O}_{3}$ & $\mathrm{MnO}$ & $\mathrm{MgO}$ & $\mathrm{CaO}$ & $\mathrm{K}_{2} \mathrm{O}$ \\
\hline Percentage\% & 14.52 & 1.66 & 0.15 & 0.005 & 0.17 & 31.94 & 0.22 \\
\hline component & $\mathrm{Na}_{2} \mathrm{O}$ & $\mathrm{TiO}_{2}$ & Loss & $\mathrm{P}_{2} \mathrm{O}_{5}$ & $\mathrm{SO}_{3}$ & $\mathrm{Cl}$ & $\mathrm{CO}_{2}$ \\
\hline Percentage\% & 0.1 & 0.058 & 4.02 & 0.94 & 45.38 & 0.027 & $<0.30$ \\
\hline
\end{tabular}

\section{Preprocessing Steps}

Mill. Mill agglomerate phosphogypsum (300 mesh), for full reaction.

Flotation Method. Add Water to phosphogypsum as the weight of phosphogypsum in 60\%.And use a blender mixing fully, let stand, with flat spoon scrape off the surface oily suspension ,repeated, until no oily suspension.

Washing Method. Water solid ratio of 3:1, use a blender mixing the soluble content of phosphorus gypsum fully dissolved in, let stand, discard the upper solution, repeat the above steps, until the phosphorus gypsum solution $\mathrm{PH}=7$.

Lime Neutralization Method. Add Water to phosphogypsum as the weight of phosphogypsum in $35 \%$, and add $3 \sim 4 \mathrm{~g}$ of quicklime, using a blender mixing, quiet place, until the liquid is neutral.

Microwave Method. Put the phosphogypsum in the microwave oven to microwave.Then, mix the phosphogypsum and citric acid which add as the weight of phosphogypsum in $0.45 \%$, and join the phosphogypsum dosage is $44 \%$ of the water in the tap water, stirring with a glass rod, fully in the blender mixing fully, let stand, adding $4 \sim 5 \mathrm{~g}$ of quicklime, using a blender mixing, quiet place, until the liquid is neutral.Liquid stand for $3 \mathrm{~h}$, remove the upper aqueous.

The content of each method before and after the pretreatment of impurities inTable2.

Gypsum Powder Preparation Method. Processed phosphogypsum, to be included in the oven, drying temperature is $150{ }^{\circ} \mathrm{C}$, time $2 \mathrm{~h}$, after drying, take fine grinding (300 mesh).

Strength Test. The mold for $160 \mathrm{~mm} \times 40 \mathrm{~mm} \times 40 \mathrm{~mm}$, water solid ratio of 1:5 after molding, casting, natural curing $2 \mathrm{~h}$ demoulding, then in the drum wind drying oven temperature $40{ }^{\circ} \mathrm{C}$ drying oven dry, measuring its flexural and compressive strength in Figure 1.

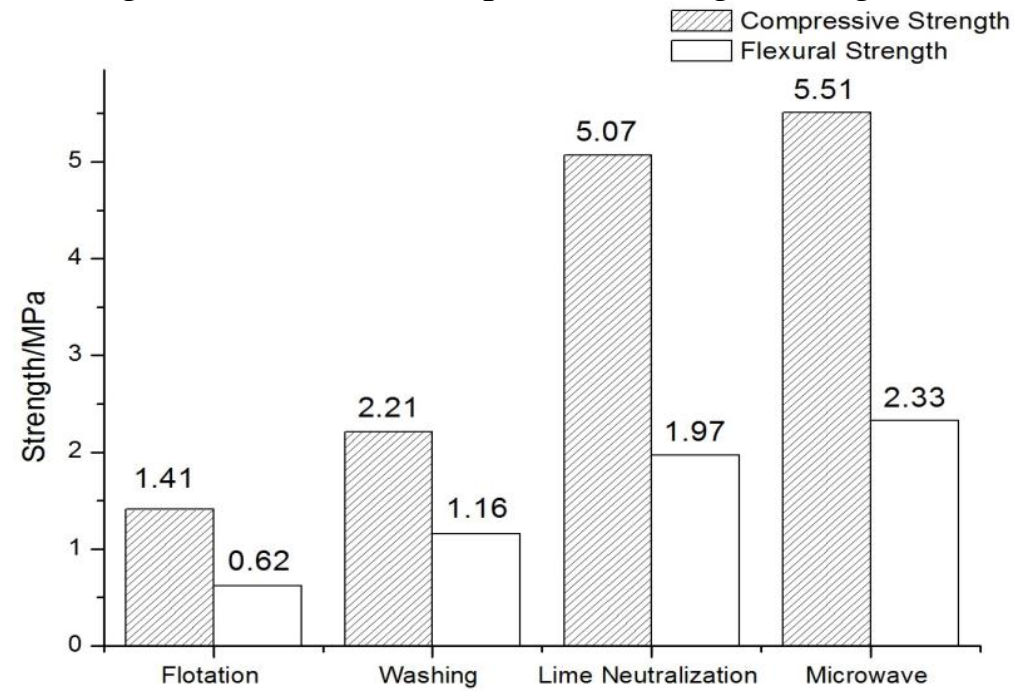

Fig.1 Flexural and compressive strength of samples after $2 \mathrm{~h}$ with pretreatment method 


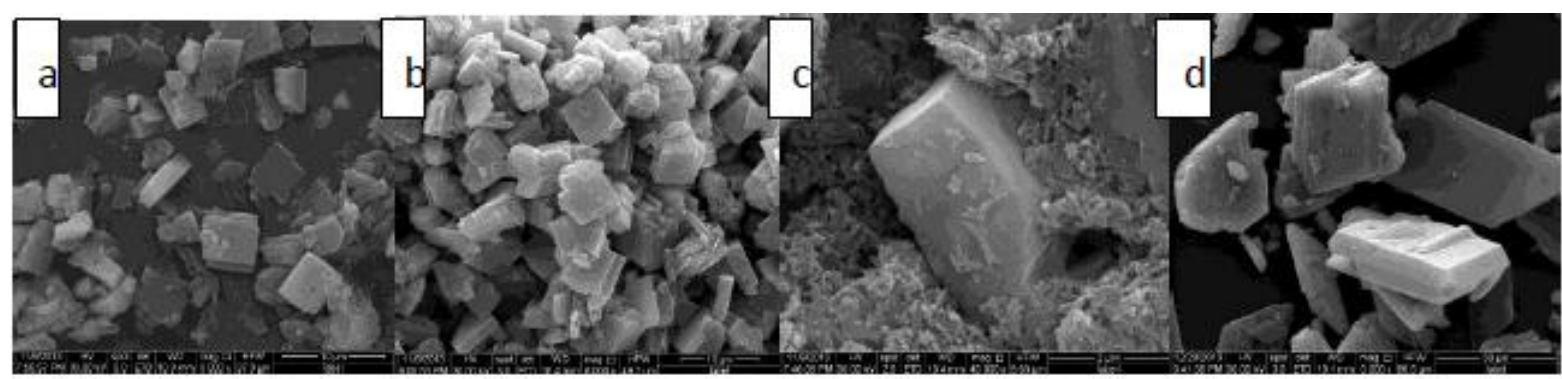

Fig.2 SEM pictures of different pretreatments on phosphogypsum(a) Washing method (b) Flotation method (c) lime neutralization method (d) Microwave method

\section{The Results}

Impurity content of phosphorus gypsum after different pretreatment are shown in Table 2 , in accordance with the national standards for the request of GB/T9776-2008 "building gypsum" .Flexural and compressive strength test sample as shown in Figure 1, the SEM of the sample morphology photos as shown in Figure 2.

Tab.2 Content of impurities before and after pretreatment/\%

\begin{tabular}{cccccc}
\hline Impurities Types & Raw Material & $\begin{array}{c}\text { Washing } \\
\text { Method }\end{array}$ & $\begin{array}{c}\text { Flotation } \\
\text { Method }\end{array}$ & $\begin{array}{c}\text { Lime } \\
\text { Neutralization } \\
\text { Method }\end{array}$ & $\begin{array}{c}\text { Microwave } \\
\text { Method }\end{array}$ \\
\hline phosphorus & 0.94 & 0.49 & 0.94 & 0.53 & 0.46 \\
fluorine & 0.12 & 0 & 0.12 & 0.06 & 0.04 \\
organic matter & 0.25 & 0 & 0.02 & 0.25 & 0 \\
gypsum content & 44.58 & 35.98 & 42.25 & 45.33 & 47.96 \\
\hline
\end{tabular}

\section{Discussion and Analysis}

\section{Flotation Method}

The principle of flotation method: because the phosphogypsum added water, the organic matter will float in surface of liquid.Use the sieve to remove oily substances.After flotation pretreatment, almost all of the organic matter removal, but the content of phosphorus and fluorine basically remain unchanged.The statistic flotation method can be seen from the figure 2:soluble phosphorus and fluorine impurities generated difficult soluble substances, makes hydration gypsum crystal morphology is poor, large length to diameter ratio, and low compressive strength.

\section{Washing Method}

The principle of water washing method: the main impurity affecting the phosphogypsum can dissolve in water.The organic impurities mainly for oily substances above can float on water.Therefore, the water washing method can remove most of the phosphorus gypsum soluble impurities, including phosphorus, fluorine, most alkali metal salts and organic impurities.For some large particles difficult soluble silica sand and other material will be suspended in the slurry, through water washing method for many times, most impurity can also be removed[6].

Can be seen from the Figure 2: hydration gypsum crystal length to diameter is larger, incomplete crystal growth, crystal surface has a small amount of suspended matter.But the flotation method pretreatment results, crystal quality significantly improved.Water washing method as simple operation, pretreatment results are good, is widely applied in the phosphorus gypsum in the pretreatment.However through the experiment, the $\mathrm{PH}=7$ on the number of washing times is commonly $3 \sim 4$ times. The wasted water will be secondary pollution to the environment. 


\section{Lime Neutralization Method}

The principle of lime neutralization method: soluble impurities are remarkably affects the performance of phosphogypsum,and add lime into phosphorus gypsum in the residual phosphate, fluoride reaction substances and fluoride phosphate, become an inert filler in the phosphogypsum that reduce the influence of soluble impurities[7][8]. Main reactions are as follows:

$$
\mathrm{P} 2 \mathrm{O} 5+3 \mathrm{Ca}(\mathrm{OH}) 2 \rightarrow \mathrm{Ca} 3(\mathrm{PO} 4) 2+3 \mathrm{H} 2 \mathrm{O}
$$

$$
2 \mathrm{~F}^{-}+\mathrm{Ca}(\mathrm{OH}) 2 \rightarrow \mathrm{CaF} 2+2 \mathrm{OH}^{-}
$$

The experimental results showed that after lime neutralization pretreatment, significantly reduce the phosphorus gypsum of phosphorus and fluorine content, but the organic matter content is unchanged .Well in Figure 2,the crystal length to diameter is smaller, crystal morphology is better, a slight overall reunion, but because of a small amount of phosphate, fluoride and organic matter not eliminate, the generated floc bond in hydration gypsum crystal surface.Using lime directly neutralizates the soluble fluorine ,phosphorus in phosphogypsum, and turned them into difficult solubleCa3(PO4)2 and $\mathrm{CaF} 2$. That can prevent soluble phosphorus in phosphogypsum and fluorine impurities to the dehydration of calcium sulphate process of change.

Lime neutralization method is easy to operate, low cost, but the residual organic matter and part of fluoride and phosphorus harmful impurities.

\section{Microwave Method}

The principle of microwave method: firstly take the advantage of the heat of microwave to deal with phosphorus gypsum, which will remove excess water and organic compounds. Secondly using citric acid turn phosphorus, fluorine impurities into water-soluble citrate, aluminate and ferrate. Thirdly,using lime directly neutralizate the rest of the soluble phosphorus ,fluorine in phosphogypsum, and turned into difficult soluble, which stop the soluble phosphorus in phosphogypsum and fluorine impurities on the influence of the dehydration of calcium sulphate transition.At the same time, neutralize the excess slurry of citric acid, etc.

Through the static,all parts of impurities and oily substances are in the upper solution. Remove the upper solution that almost all organic matter, part of phosphorus and fluorine content of harmful impurities are removed.

The experimental results showed that after pretreatment by microwave method, organic matter and phosphorus in phosphogypsum, fluorine content decreased significantly.As can be seen from the Figure 2, the sample length to diameter is small, the crystal plate is more, appear a little reunion phenomenon, almost no suspended floc surface.

Microwave method is simple, effective, convenient for industrial production, mostly in the pretreatment of phosphogypsum in addition to organic matter and phosphorus, fluorine harmful impurities, suitable for phosphogypsum pretreatment of good quality.

\section{Conclusions}

1. The flotation method is to remove the organic material in the phosphogypsum, but it is hard to remove all.And hydration gypsum crystal morphology is poorer, large length to diameter ratio and compressive strength and low sample.

2. The washing method is to remove the tiny insoluble impurity in the phosphogypsum, such as free phosphoric acid, water soluble phosphate and fluoride.But the demand of water is big, which causes secondary pollution.

3. The lime neutralization method is particularly simple and effectively to remove the residual acid in the phosphogypsum.But residual organic matter and part of fluoride and phosphorus harmful impurities will infect the compressive strength, flexural strength. At the same time, the appearance of the organic matter can also affect the construction gypsum products color. 
4. The microwave method is to remove the organic material in the phosphogypsum and phosphorus in phosphogypsum fluorine harmful impurities, less consumption and gypsum.Hydration gypsum crystal morphology, length to diameter is small, and the samples have higher compressive and flexural strength.

\section{Acknowledgements}

This work financially supported by Natural Science Foundation (51264017).

※Corresponding author:Zhao zhiman,provide phone:86-13529317921; Fax:86-0871-63864560

\section{References}

[1]Wang Qiqing:Building materials and application of gypsum.Beijing:Chemical Industry Press, 2008:16-17.

[2]Zeng Ming,Ruan Yan, Chen Jing, et al.Comarison of different processing method of phosphogypsum.Building World, 2011; 6:18-21.

[3] Xiang Caiwang, Gypsum and products, Beijing: China Building Materials Industry, 1998:17-18.

[4]Ye Xuedong, Phosphogypsum utilization present situation, problems and Suggestions in our country[J]. Phosphate fertilizer and compound fertilizers, 2011, 26(1):5-7.

[5]Yang Peihao, The comprehensive utilization of phosphogypsum[J]. China resources comprehensive utilization 2009,27(1):13-15.

[6]Jia Xingwen, Wu Zhou, Ma Ying. Phosphorus gypsum building materials resource utilization[J]. Material review,2013, 27(12):139-146.

[7]Yang Yuehua, Shu Yizhou, Think about the utilization of phosphogypsum in yunnan province[J]. Inorganic salt industry, 2012, 44(12):4-8.

[8] Du Lushan, Ming Dazeng, et al. The use of phosphogypsum and recycling [J]. Journal of chemical technology and development, 2010, 33 (4) 625 - 28. 